\title{
Gamificando a Sala de Aula: Um Relato de Experiência com o Kahoot na Chapada Diamantina
}

\author{
Ana Luísa dos Santos Carregosa ${ }^{1}$, Douglas de Souza Araujo ${ }^{1}$, \\ Monck Charles Nunes de Albuquerque ${ }^{1}$ \\ ${ }^{1}$ Instituto Federal de Educação, Ciência e Tecnologia da Bahia - IFBA \\ Seabra - BA - Brasil
}

\begin{abstract}
This article aims to analyze and discuss hybrid teaching, which is emerging as a novelty in teaching methodology. We hope through this work to demonstrate the effects of using a game-based learning platform applied to education. The approach used was an experimentation evolving gamification method using the Kahoot! in high school classes. As a research result, we found that digital technologies associated with educational practices transform the school environment in a more attractive and constitutes a tool with high potential to learning/teaching process.
\end{abstract}

Resumo. Esse artigo tem como objetivo analisar e discutir a temática do ensino hibrido, que está se destacando como uma novidade na metodologia de ensino. Almejamos através desse trabalho, demonstrar os efeitos da utilização de plataforma de aprendizagem baseada em games aplicado à educação. A abordagem utilizada para tal, se deu através de um experimento pelo método da gamificação com o uso da ferramenta Kahoot! em aulas de Informática Básica no Ensino Médio Técnico. Isto posto, se constatou que as tecnologias digitais associadas às práticas educacionais tornam o ambiente escolar mais atrativo e se constitui como uma ferramenta com alto potencial para o processo ensino/aprendizagem.

\section{Introdução}

Nos últimos anos, pesquisadores tem discutido e analisado as mudanças da sociedade, alicerçadas pelas tecnologias. Para [Kohn and Moraes 2007] a tecnologia e seus dispositivos influenciam diretamente a construção de uma nova cultura digital. Para [Albuquerque et al. 2017] a sociedade está cada vez mais presente em uma sociedade virtual, marcada pela Presencialidade Virtual. Portanto, essas mudanças da sociedade abrangem também o nível acadêmico, fazendo-se necessário buscar novos meios que visem ampliar a forma de educar, para que haja uma compatibilidade com o novo cenário mundial, que é definido por [Castells et al. 2007] como a sociedade em rede.

Neste contexto, a educação é considerada como sinônimo de algo pouco atrativo, principalmente entre os jovens, circunstância que é estipulada por [Tolomei 2017] como uma crise motivacional, pois não há, em sua maioria, um engajamento nas transições da sociedade em rede no setor juvenil e a escola, resultando em um desinteresse do aluno com o modo de ensino tradicional. Sendo assim, é fundamental se pensar em meios que interliguem às Tecnologias Digitais da Informação e Comunicação - TDICs com o processo de ensino-aprendizagem escolar. 
VIII Congresso Brasileiro de Informática na Educação (CBIE 2019)

Anais do XXV Workshop de Informática na Escola (WIE 2019)

Para [da Rocha Seixas et al. 2016] e [Costa et al. 2018] a gamificação é uma abordagem que pode auxiliar o problema da motivação no contexto educacional, através de elementos presentes em jogos, os quais proporcionam um engajamento no processo de ensino-aprendizagem. Nesse sentido, o Kahoot! é um ambiente gameficado que possibilita essa avaliação [Dellos 2015].

Ademais, [Catindig and Prudente 2019] outrora escreveram sobre o uso do Kahoot! como uma ferramenta auxiliadora no ensino de ondas para uma avaliação somativa. Assim sendo, utilizaram dois grupos nomeados A e B para a aplicação de uma revisão. O primeiro grupo fez o uso da ferramenta apresentada e, o segundo, obteve uma revisão denominada tradicional. Os resultados da avaliação proposta posteriormente revelaram que o grupo A obteve melhor aproveitamento em relação ao grupo B.

Este trabalho busca analisar por meio da gamificação, o processo de desenvoltura motivacional dos estudantes e seus resultados diante de uma nova metodologia de ensino. As turmas que iniciam o curso técnico apresentam um índice alto de desistência. Por esse motivo foi escolhido duas turmas do primeiro ano do ensino médio, pela razão de ser o primeiro contato dos ingressantes com a disciplina de informática básica.

\section{Metodologia}

A proposta de ensino gamificado foi empregada pelos monitores participantes do Projeto de Monitoria Básica do IFBA - campus Seabra, dentro das salas de aula e laboratórios de informática que a instituição dispõe, usados de acordo com as atividades desempenhadas nesse processo. Foram ministradas aulas de introdução à informática durante três meses dentro dessas dependências, abrangendo duas turmas de primeiro ano do ensino médio da modalidade de curso integrado no turno vespertino, uma de Informática e outra do curso de Meio Ambiente, as duas turmas compostas por 30 alunos de ambos os sexos.

Os conteúdos aplicados em ambas as turmas foram os mesmos e divididos em módulos, distribuídos da seguinte maneira: Conceitos Iniciais de Informática, Hardware, Software e Aplicativos de Escritório. As aulas eram organizadas conciliando teoria e prática, além disso, para que o conteúdo ficasse bem compreendido entre os discentes, foram disponibilizados os materiais usados em aula, bem como um material de apoio, como apostilas, exercícios, referências de pesquisa, entre outros.

O método de ensino utilizado, centrou-se em primeiro momento na forma tradicional para ambas as turmas, no entanto, as aulas de revisão antes da avaliação se distinguiam, uma vez que a turma do curso de Meio Ambiente dispunha de aulas tradicionais, com as revisões dos assuntos seguindo essa mesma forma de ensino. Já a turma de Informática, também seguia o modelo de aulas tradicionais, entretanto, as revisões contavam com o uso de uma plataforma de aprendizagem baseada em jogos, o Kahoot!.

Esse ambiente educacional gamificado, empregado nas aulas de revisão da turma de informática, teve como principal instrumento explorado, o Quiz, que se caracteriza como um jogo baseado em perguntas e respostas que ajuda a tornar o ambiente de aprendizado instigante. Segundo [Licorish et al. 2018], essa ferramenta se define como um sistema de resposta que provoca demasiado engajamento entre os estudantes e instiga uma melhor experiência e dinâmica em sala de aula, minimizando distrações e oferecendo uma melhor qualidade de ensino. 
VIII Congresso Brasileiro de Informática na Educação (CBIE 2019)

Anais do XXV Workshop de Informática na Escola (WIE 2019)

Nesse sistema, foram criados testes com 20 perguntas com 4 alternativas cada, havendo apenas uma correta, elaboradas a partir dos conteúdos abordados em sala. A turma de Informática foi dividida em seis grupos de cinco integrantes e cada equipe possuía 20 segundos para responder as perguntas efetuadas. Assente nas respostas, era informado um feedback com os resultados das equipes e um ranking acumulativo de pontos. Feitas as revisões, ambas as turmas realizaram uma avaliação objetiva de múltipla escolha elaborada com 10 questões e, por fim, foi aplicado um questionário aos estudantes que tiveram contato com as revisões de ensino gamificado.

\section{Resultados e Discussões}

Nesta seção, apresenta-se os resultados obtidos com a experiência de gamificar a sala de aula com o Kahoot!. Na (Figura 1) é apresentado o resultado da comparação do teste final aplicado nas duas turmas.

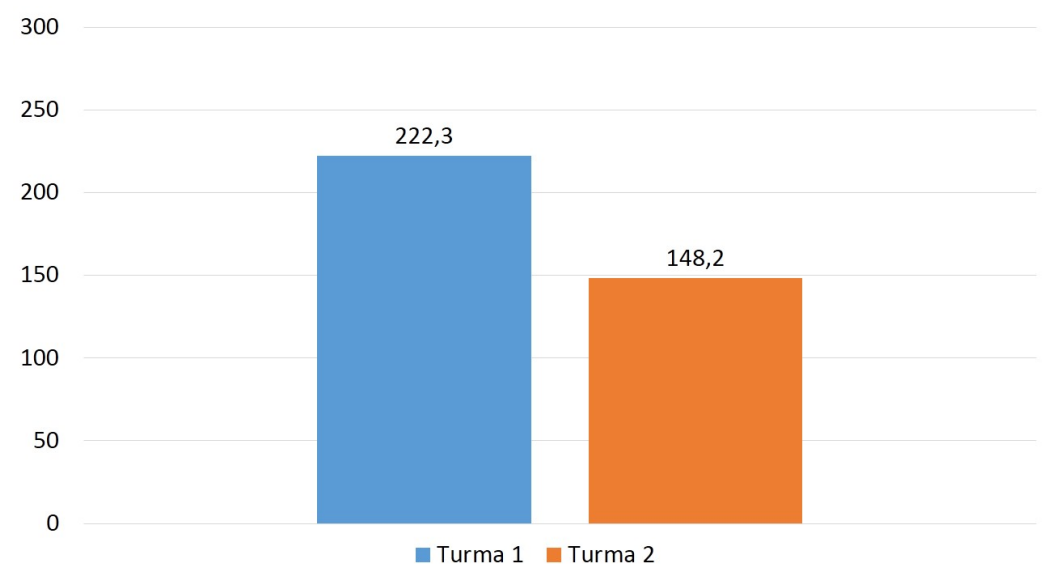
Figura 1. Pontuação obtida no teste final. Azul - Turma que fez uso da
gamificação; Laranja - turma que nao fez uso da gamificação.

Do total de 300 pontos, a turma experimental, caracterizada pela cor azul, obteve um resultado de 222,3 pontos. Já a turma controle, caracterizada pela cor laranja, atingiu um resultado mais abaixo com 148,2 pontos. Em vista disso, é notável uma diferença de 72,1 pontos entre os dois scores apresentados.

Tabela 1. Comparação geral entre as duas turmas

\begin{tabular}{|c|c|c|c|}
\hline Estudantes & $\begin{array}{c}\text { Total } \\
\text { Alunos }\end{array}$ & $\begin{array}{c}\text { Total } \\
\text { pontos }\end{array}$ & $\begin{array}{c}\text { Total } \\
\text { Média }\end{array}$ \\
\hline Turma 1 & 30 & 222,3 & 7,4 \\
\hline Turma 2 & 30 & 148,2 & 4,94 \\
\hline
\end{tabular}

A tabela abrange uma visão ampliada, relacionando o total de estudantes e as médias de cada turma. Em comparação com a pesquisa de [Catindig and Prudente 2019] houve um aumento de 1,19 pontos na diferença da média dos dois grupos utilizados. Enquanto o trabalho anterior obteve 1,27 pontos como resultado da subtração, presente na equação grupo experimental menos grupo controle, o trabalho atual atingiu 2,46 pontos. 
VIII Congresso Brasileiro de Informática na Educação (CBIE 2019)

Anais do XXV Workshop de Informática na Escola (WIE 2019)

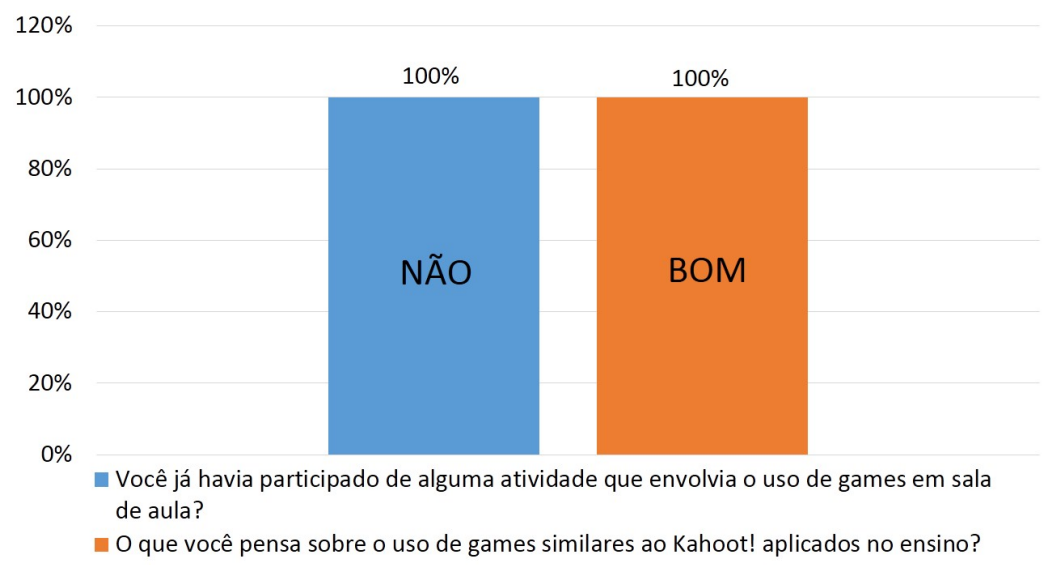

Figura 2. Questionamento realizado nas turmas1 (experimental) acerca da ex-
periência de uso da gamificação

O gráfico na figura 2 buscou apresentar as repostas dos participantes, do grupo experimental, em relação à experiência realizada. Na primeira coluna é possível observar que os estudantes nunca tiveram contato com uma aplicabilidade do tipo gamificado. As causas podem ser diversas, como o fato da maioria dos entrantes se situarem em locais com internet escassa. Ademais, na segunda coluna é visível que os alunos recomendam o uso do ensino diferenciado, fato idealizado por [Alves 2014], que escreve sobre o estímulo dos jovens em relação aos games.

Segundo [Martins and Giraffa 2018] ao se tratar de jogabilidade educacional são significantes ferramentas que promovam um aperfeiçoamento da vida estudantil, ou seja, que aprimorem os conhecimentos teóricos que serão exigidos e fatores presentes no social do indivíduo. Tal afirmação engloba o ambiente utilizado e gamificado Kahoot! pois promove, como ratificado, o ensino da Informática Básica e uma cooperação em conjunto dos estudantes em busca de um resultado que englobe as felicitações de todos os componentes do grupo, perpassando por um caminho competitivo, motivacional e educador em prol de um bem coletivo.

Desse modo, houve elevada taxa de rendimento dos entrantes que participaram da revisão gamificada, que garantiram um resultado proeminente na avaliação de Informática Básica. Para além de números, o fator comportamental mostrou-se eficiente, já que o engajamento e dedicação salientada dos estudantes ao se depararem com o "novo" se traduziu em uma motivação exacerbada. Logo, por se tratar de uma matéria diferenciada e incomum nos currículos escolares, resultados como estes tornam-se um importante fator para o auxílio do entendimento da aplicabilidade de uma educação que busque satisfazer demandas de aprendizagem tanto de docentes quanto discentes.

\section{Considerações finais}

O presente estudo fez uma análise do uso da gamificação em uma sala de aula por meio da ferramenta kahoot! em aulas de revisão de conceitos sobre Informática Básica. A ferramenta foi moldada de acordo com assuntos já vistos, e aplicada como método revisional em apenas uma das turmas.

Os resultados obtidos por meio do teste apontam que foi uma experiência nova 
VIII Congresso Brasileiro de Informática na Educação (CBIE 2019)

Anais do XXV Workshop de Informática na Escola (WIE 2019)

para os alunos, de fácil aplicação e que proporciona uma melhoria no processo de ensinoaprendizagem. Neste sentido, a proposta de gamificar utilizando o Kahoot! demonstrouse bastante promissora pela capacidade de promover o engajamento estudantil, como também a interatividade dos alunos em sala. Foi observado uma melhora no quesito motivacional na turma experimental, obtendo assim uma resposta favorável a problemática proposta, ao afirmar a possibilidade da relação entre motivação e ensino através de aulas gamificadas por meio da ferramenta kahoot!.

Por fim, como trabalhos futuros, pretende-se agregar a realidade aumentada e a realidade virtual na ferramenta e aplicar em outras turmas com outros assuntos e com maior tempo de duração.

\section{Referências}

Albuquerque, M., Sales, G. L., Rebouças Filho, P., and Medeiros, C. (2017). Avaliação da presencialidade em um fórum lv utilizando lógica fuzzy. In Brazilian Symposium on Computers in Education (Simpósio Brasileiro de Informática na Educação-SBIE), volume 28, page 1357.

Alves, L. (2014). A cultura lúdica e cultura digital: interfaces possíveis.

Castells, M. et al. (2007). A sociedade em rede, volume 1. Paz e Terra São Paulo.

Catindig, J. and Prudente, M. S. (2019). Effectiveness of kahoot as a revision tool in studying waves. In Proceedings of the 10th International Conference on E-Education, E-Business, E-Management and E-Learning, pages 119-123. ACM.

Costa, R., Bernardo, A. L., and de Lucena, I. M. M. (2018). Incentivando a aprendizagem de arquitetura de computadores em cursos de computação através de um simulador do microprocessador z-80 com kahoot! In Anais do Workshop de Informática na Escola, volume 24, page 710 .

da Rocha Seixas, L., Gomes, A. S., and de Melo Filho, I. J. (2016). Effectiveness of gamification in the engagement of students. Computers in Human Behavior, pages 48-63.

Dellos, R. (2015). Kahoot! a digital game resource for learning. International Journal of Instructional Technology and Distance Learning, 12(4):49-52.

Kohn, K. and Moraes, C. H. (2007). O impacto das novas tecnologias na sociedade: conceitos e características da sociedade da informação e da sociedade digital. In $X X X$ Congresso Brasileiro de Ciências da Comunicação, volume 30, pages 1-13.

Licorish, S. A., Owen, H. E., Daniel, B., and George, J. L. (2018). Students' perception of kahoot!'s influence on teaching and learning. Research and Practice in Technology Enhanced Learning, 13(1):9.

Martins, C. and Giraffa, L. M. M. (2018). Possibilidades de ressignificações nas práticas pedagógicas emergentes da gamificação. ETD-Educação Temática Digital, 20:5-26.

Tolomei, B. V. (2017). A gamificação como estratégia de engajamento e motivação na educação. EAD em foco, 7(2). 